\title{
СЫВОРОТОЧНЫЕ ПОКАЗАТЕЛИ СИСТЕМЫ ЦИТОКИНОВ У БОЛЬНЫХ ХГ С
}

\section{SERUM INDICATORS OF THE CYTOKINE SYSTEM IN PATIENTS WITH CHRONIC HEPATITIS C}

\section{A. Muskhadzhiev}

Summary. The article shows that the assessment of serum levels of TGF- $\beta 1$ and TIMP-1 provides new information for characterizing the activity and stage of chronic hepatitis C. Dynamics of serum levels of TGF- $\beta 1$ and TIMP-1 serves as an informative test for monitoring the effectiveness of treatment of patients with chronic hepatitis C with INF-a drugs. and ribavirin.

Keywords: cytokines, blood serum, clinical features, genotype, asthenic syndrome.

\author{
Мусхаджиев Алимхан Абухаджиевич \\ К.м.н., ассистент, ФГБОУ ВО «Дагестанский \\ государственный медицинский университет» МЗ РФ \\ muskhadzhiyev76@list.ru
}

Аннотация. В статье показано, что оценка сывороточных уровней TGF- $\beta 1$ и ТИМП-1 дает новую информацию для характеристики активности и стадии ХГ С. Динамика сывороточных уровней TGF- $\beta 1$ и ТИМП-1 служит информативным тестом для контроля эффективности лечения больных ХГ С препаратами ИНФ-а и рибавирина.

Ключевые слова: цитокины, сыворотка крови, клинические особенности, генотип, астенический синдром.
И сследование уровня цитокинов TGF- $\beta 1$ и ТИМП-1 в сыворотке крови проведено 150 больным ХГ С в возрасте от 19 до 59 лет (средний возраст $36,7 \pm 9,2$ лет) на базе медицинского центра «Гепар» г. Махачкала. При этом установлено: содержание TGF-1 $\beta$ было повышено у 103 (68,7\%) больных, понижено у 20 $(13,3 \%)$ и соответствовало показателям здоровых лиц у $27(18,0 \%)$ больных ХГ С. Среднее значение TGF- $\beta 1$ составило $529,8 \pm 118,8$ пг/мл., что значимо $(p<0,01)$ повышено по сравнению с соответствующими данными кон-

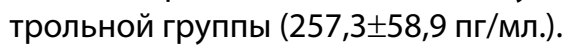

Содержание ТИмП-1 в сыворотке крови было повышено у 114 (76\%) больных ХГС, понижено у 17 (11,3\%) и соответствовало показателям группы контроля у 19 (12,7\%). Средний показатель ТИМП-1 также достоверно $(p<0,01)$ отличался от такового контрольной груп-

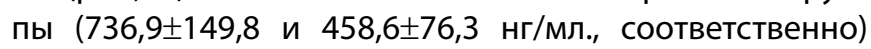
(таблица 1).

Таким образом, у больных ХГ С показатели цитокинов TGF- $\beta 1$ и ТИМП-1 в сыворотке крови были значимо повышены по сравнению с соответствующими значениями контрольной группы.
Изучение уровня исследованных цитокинов в зависимости от пола, возраста больных, путей инфицирования ХГ С значимой разницы не выявило.

При исследовании содержания цитокинов в зависимости от длительности заболевания установлено, что при анамнезе болезни более 10 лет показатели TGF- $\beta 1$ и ТИМП-1 были повышены по сравнению с таковыми с более коротким анамнезом. Но при изучении корреляционных взаимосвязей достоверной разницы при этом не выявлено ( $r=0,20, r=0,24, p>0,05$, соответственно) (таблица 2).

Изучение содержания цитокинов в сыворотке крови в зависимости от выраженности астенического синдрома показало, что при оценке степени астении в 1 балл уровень TGF- $\beta 1$ и ТИМП-1 были повышены по сравнению с соответствующими значениями больных в 0 баллов. При изучении корреляционных связей установлено наличие прямой связи между TGF- $\beta 1$ и ТИМП- 1 , с одной стороны, и выраженностью астенического синдрома, с другой, но при этом достоверной взаимосвязи не выявлено ( $r=0,32, p>0,05, r=0,26, p>0,05$, соответственно) (рис. 1). 


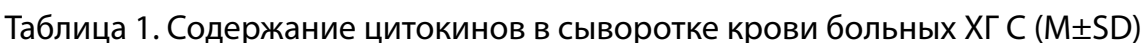

\begin{tabular}{|l|l|l|}
\hline Группа & TGF- $\beta$ 1, пг/мл. & ТИМП-1, нг/мл. \\
\hline Больные ХГ С, $\mathrm{n}=150$ & $529,8 \pm 118,8$ & $736,9 \pm 149,8$ \\
\hline Здоровые, $\mathrm{n}=35$ & $257,3 \pm 58,9$ & $458,6 \pm 76,3$ \\
\hline Значение $\mathrm{p}$ & $p<0,01$ & $p<0,01$ \\
\hline
\end{tabular}

Таблица 2. Содержание цитокинов в сыворотке крови у больных ХГ С в зависимости от длительности заболевания $(\mathrm{M} \pm \mathrm{SD})$

\begin{tabular}{|l|l|l|}
\hline Анамнез болезни & TGF- $\beta 1$, пг/мл. & ТИМП-1, нг/мл. \\
\hline До 10 лет & $584,2 \pm 108,4$ & $784,8 \pm 132,4$ \\
\hline Более 10 лет & $652,3 \pm 132,2$ & $842,2 \pm 154,8$ \\
\hline Значение $р$ & $p>0,05$ & $p>0,05$ \\
\hline
\end{tabular}

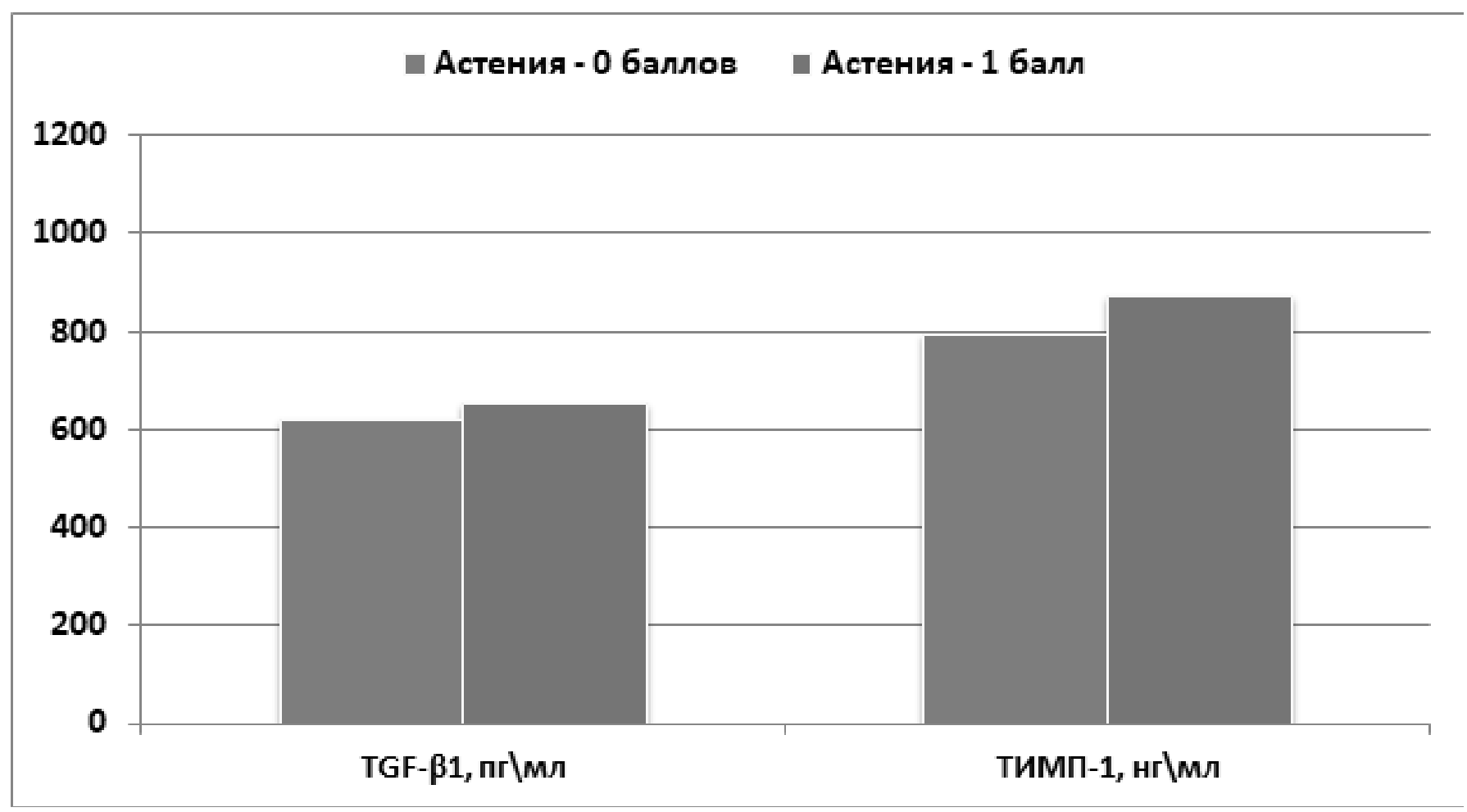

Рис. 1. Содержание цитокинов в сыворотке крови в зависимости от выраженности астенического синдрома. 
Таблица 3. Сравнительный анализ содержания цитокинов в сыворотке крови у больных ХГ

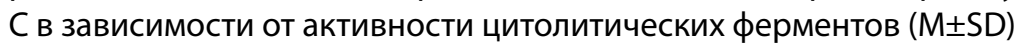

\begin{tabular}{|c|c|c|}
\hline Больные ХГ С & TGF- $\beta 1$, пг/мл. & тИмП-1, нг/мл. \\
\hline АлАТ/АсАТ до 1,5 N. & $434,8 \pm 95,7$ & $633,1 \pm 90,6$ \\
\hline АлАТ/АсАТ 1,5-3 N. & $576,8 \pm 115,1$ & $781,7 \pm 150,2$ \\
\hline АлАТ/АсАТ 3-5 N. & $683,4 \pm 100,1$ & $860,5 \pm 182,5$ \\
\hline Контроль, n=35 & $257,3 \pm 58,9$ & $458,6 \pm 76,3$ \\
\hline Значение $\mathrm{p}$ & $\begin{array}{l}p 1-2<0,05 \\
\text { p1-3<0,05 } \\
\text { p2-3<0,05 } \\
\text { p1-4<0,05 } \\
\text { p2-4<0,01 } \\
\text { p3-4<0,01 }\end{array}$ & $\begin{array}{l}\text { p1-2<0,05 } \\
\text { p1-3<0,05 } \\
\text { p2-3<0,05 } \\
\text { p1-4<0,05 } \\
\text { p2-4<0,01 } \\
\text { p3-4<0,01 }\end{array}$ \\
\hline
\end{tabular}

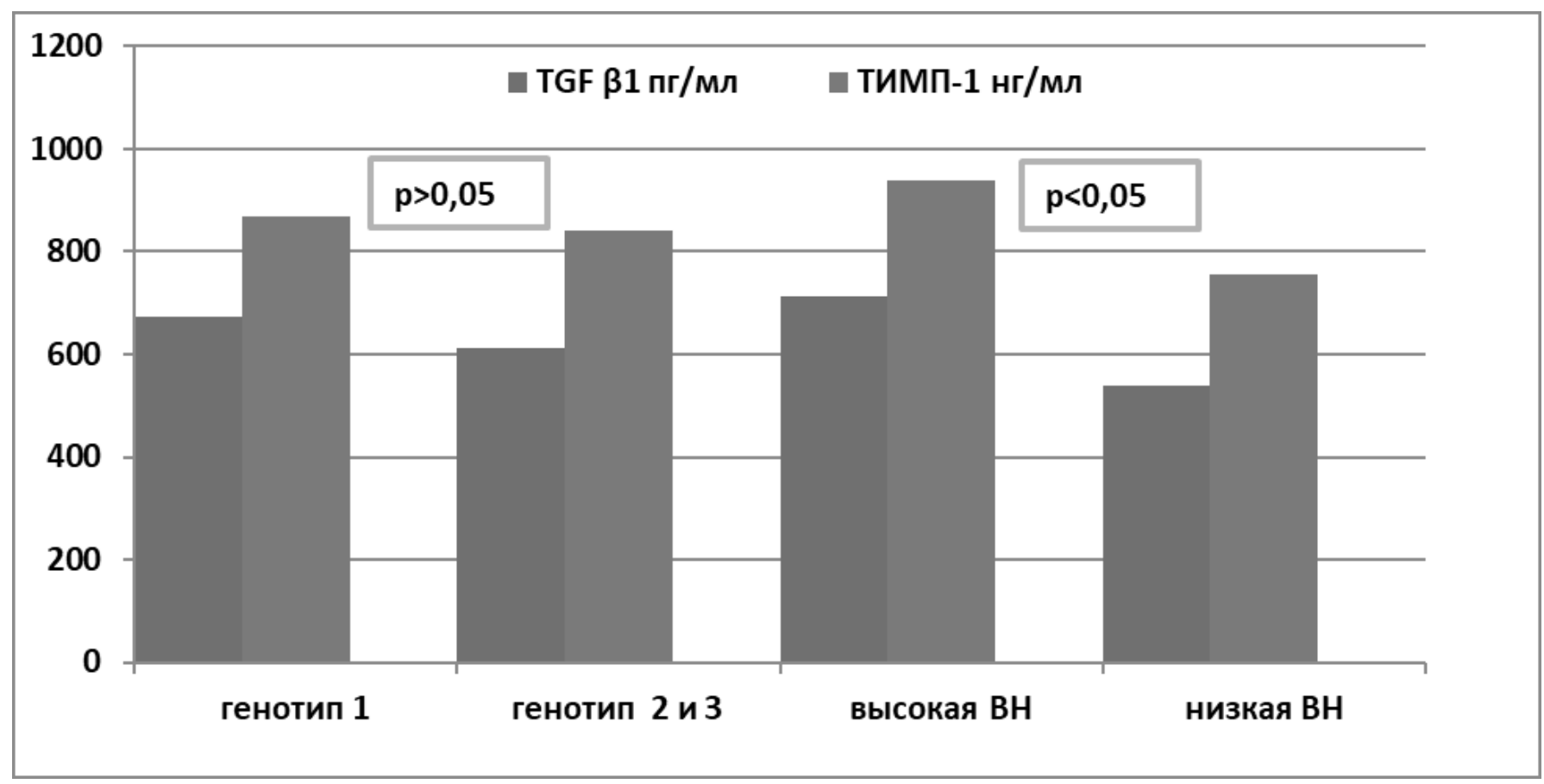

Рис. 2. Сравнительная оценка концентрации цитокинов в зависимости от генотипа ВГ С и вирусной нагрузки ( $>>0,05)$. 


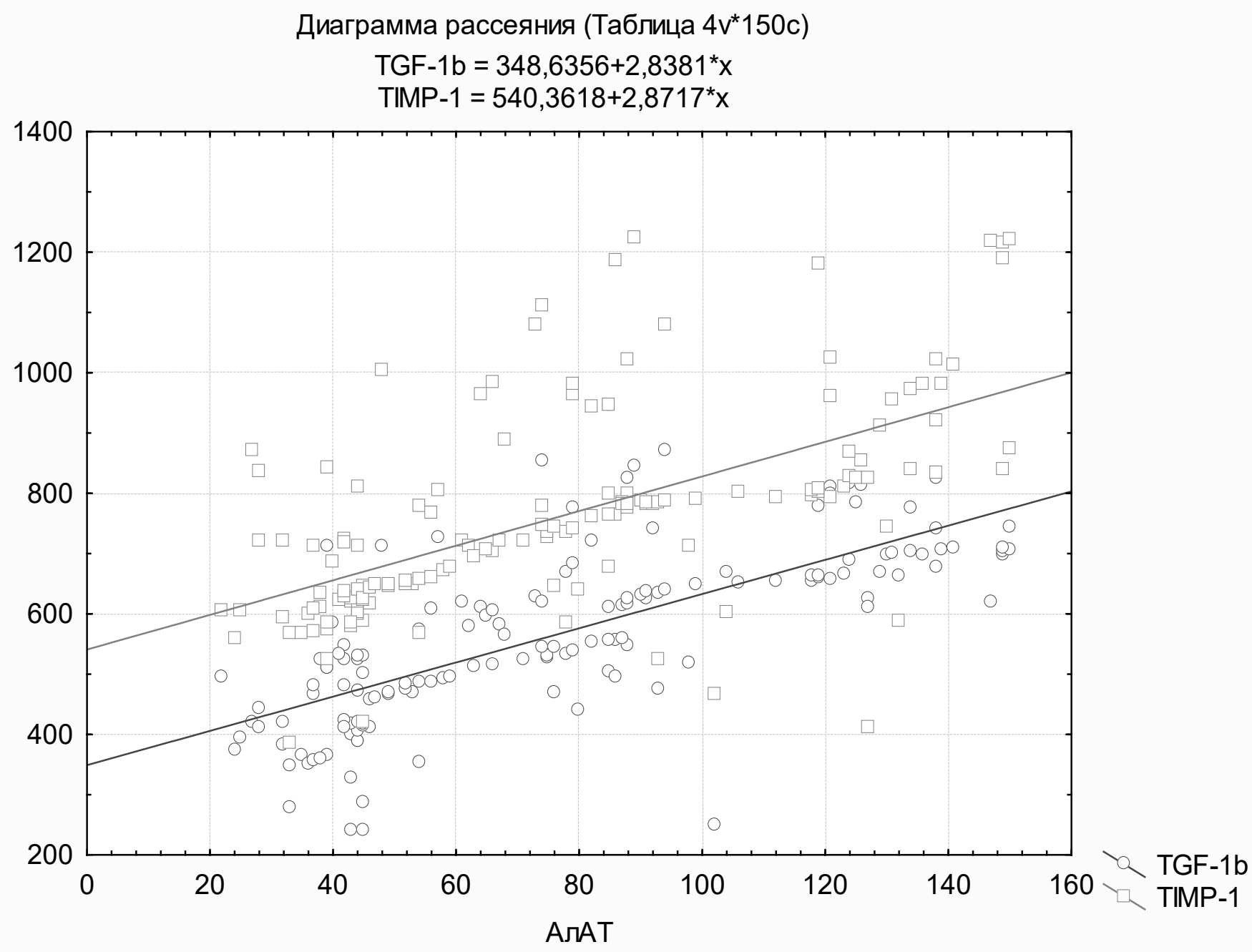

Рис. 3. Корреляционная зависимость между содержанием АлАТ в сыворотке крови и концентрацией TGF- $\beta 1$ (пг/мл.), ТИМП-1 (нг/мл.) у больных ХГ C ( $r=0,61, r=0,68, p<0,01$, соответственно).

Из объективных симптомов и по данным УзИ у большинства больных ХГ С отмечалось увеличение печени различной степени выраженности. Содержание TGF- $\beta 1$ и ТИМП-1 было также повышено в сыворотке крови в зависимости от размеров увеличения печени, но достоверной связи при этом не установлено ( $>>0,05)$.

Таким образом, при исследовании уровня цитокинов в сыворотке крови в зависимости от клинических особенностей заболевания нами установлено повышение содержания TGF- $\beta 1$ и ТИМП-1 по мере нарастания длительности анамнеза заболевания, выраженности астенического синдрома и степени увеличения размеров печени.

При изучении возможных взаимосвязей между показателями цитокинов в зависимости от генотипа ВГ С и вирусной нагрузки нами установлены следующие результаты. У больных ХГ С генотипом 1 уровень TGF- $\beta 1$ был повышен по сравнению с таковыми пациентов с генотипами 2 и 3 . Но при этом достоверной разницы между исследуемыми группами установлено не было. По содержанию ТИМП-1 больные ХГ С в зависимости от генотипа достоверно не отличались между собой $(p>0,05)$.

Уровень содержания TGF- $\beta 1$ у исследованных больных ХГ С высокой вирусной нагрузкой был значимо повышен по сравнению с соответствующими показателями при низкой вирусной нагрузке. При изучении корреляционных взаимосвязей между ними выявлена достоверная связь (712,5 $\pm 72,2 ; 538,2 \pm 68,3$ соответственно) $(p<0,05)$. Аналогичная корреляция прослеживалась при оценке средних концентрации ТИМП-1 в указанных группах, т.е. уровень ТИМП-1 в группе больных ХГ С высокой вирусной нагрузкой был значимо выше по сравнению с таковыми при низкой вирусной нагрузке $(938,1 \pm 92,7$; $754 \pm 81,3$ соответственно) $(p<0,05)$ (рис. 2). 


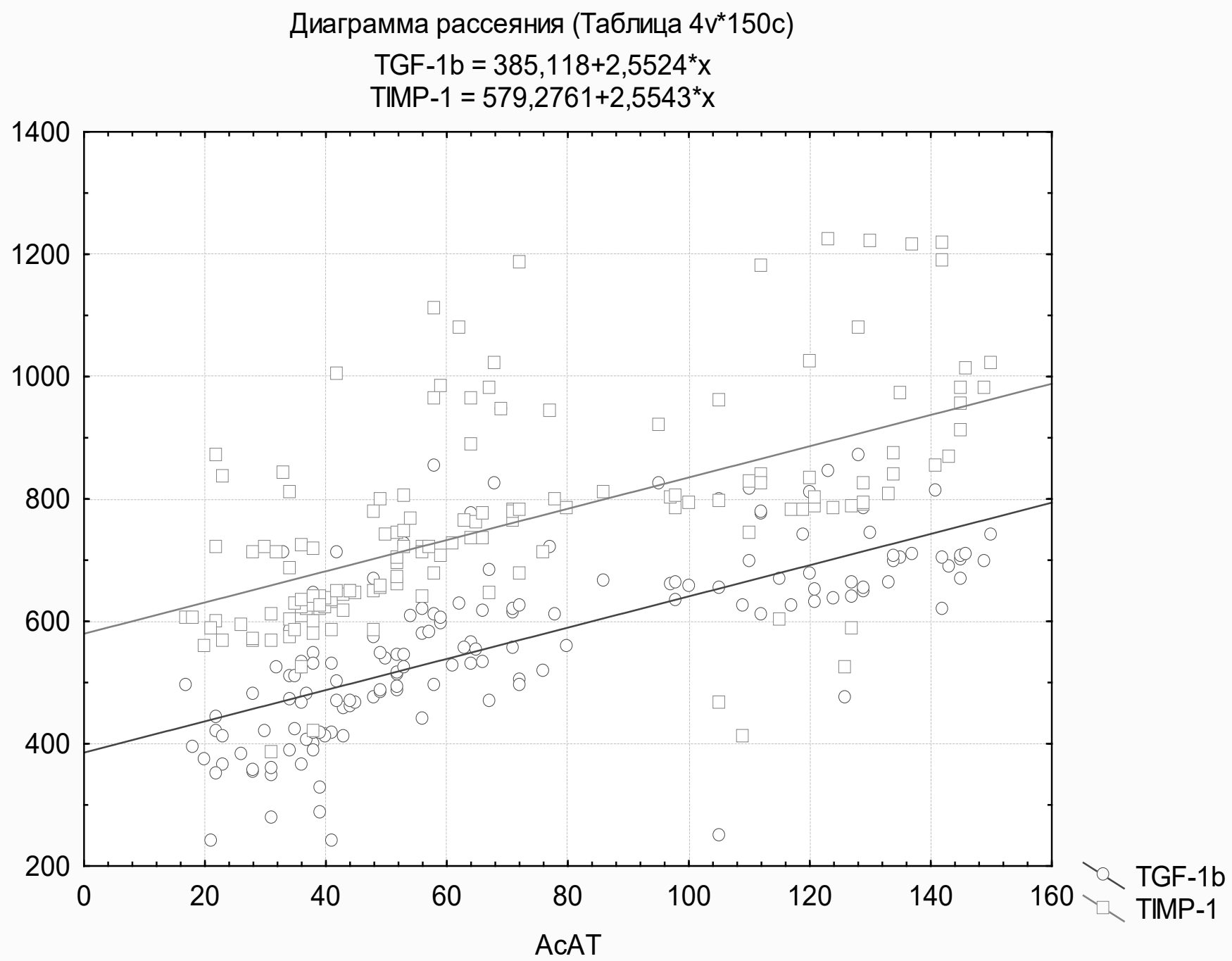

Рис. 4. Корреляционная зависимость между содержанием АсАТ в сыворотке крови и концентрацией TGF- $\beta 1$ (пг/мл.), ТИМП-1 (нг/мл.) у больных ХГ C ( $r=0,58, r=0,62, p<0,01$, соответственно).

Сравнительная характеристика сывороточных показателей цитокинов в зависимости от активности цитолитических ферментов показана в таблице 3.

Как видно из таблицы 3, средняя концентрация TGF- $\beta 1$ у исследованных больных ХГ С в зависимости от активности АлАТ/АсАТ с минимальной активностью цитолитических ферментов $(434,8 \pm 95,7)$ значимо $(p<0,05)$ была понижена по сравнению с показателем у пациентов с активностью АлАТ/АсАТ 1,5-3 норм и 3-5 норм $(576,8 \pm 115,1$ и 683,4 $\pm 100,1$, соответственно). Средний показатель ТИМП-1 у пациентов с активностью АсАТ/АлАТ до 1,5 норм $(633,1 \pm 90,6)$ был также значимо $(p<0,05)$ ниже по сравнению с содержанием данного цитокина при незначительной и умеренной цитолитической активности $(781,7 \pm 150,2$ и $860,5 \pm 182,5$, соответственно).
При изучении зависимости между содержанием цитокинов в сыворотке крови и концентрацией цитолитических ферментов у больных ХГ С нами установлены следующие результаты. Выявлена прямая значимая корреляционная взаимосвязь между концентрацией TGF- $\beta 1$ и ТИМП-1, с одной стороны и уровнем АлАТ/АсАТ, с другой $(r=0,61, r=0,58, p<0,01$ и $r=0,68, r=0,62, p<0,01$, соответственно) (рис. 3,4).

Исследование содержания цитокинов в зависимости от других биохимических показателей (билирубина, альбумина, общего белка, ГГТ, ЩФ) у больных ХГ С достоверной связи не обнаружило ( $>>0,05)$.

При исследовании зависимости показателей TGF- $\beta 1$ и ТИМП-1 в сыворотке крови от ПЭ у больных ХГ С установлено, что по мере нарастания их концентраций, ста- 


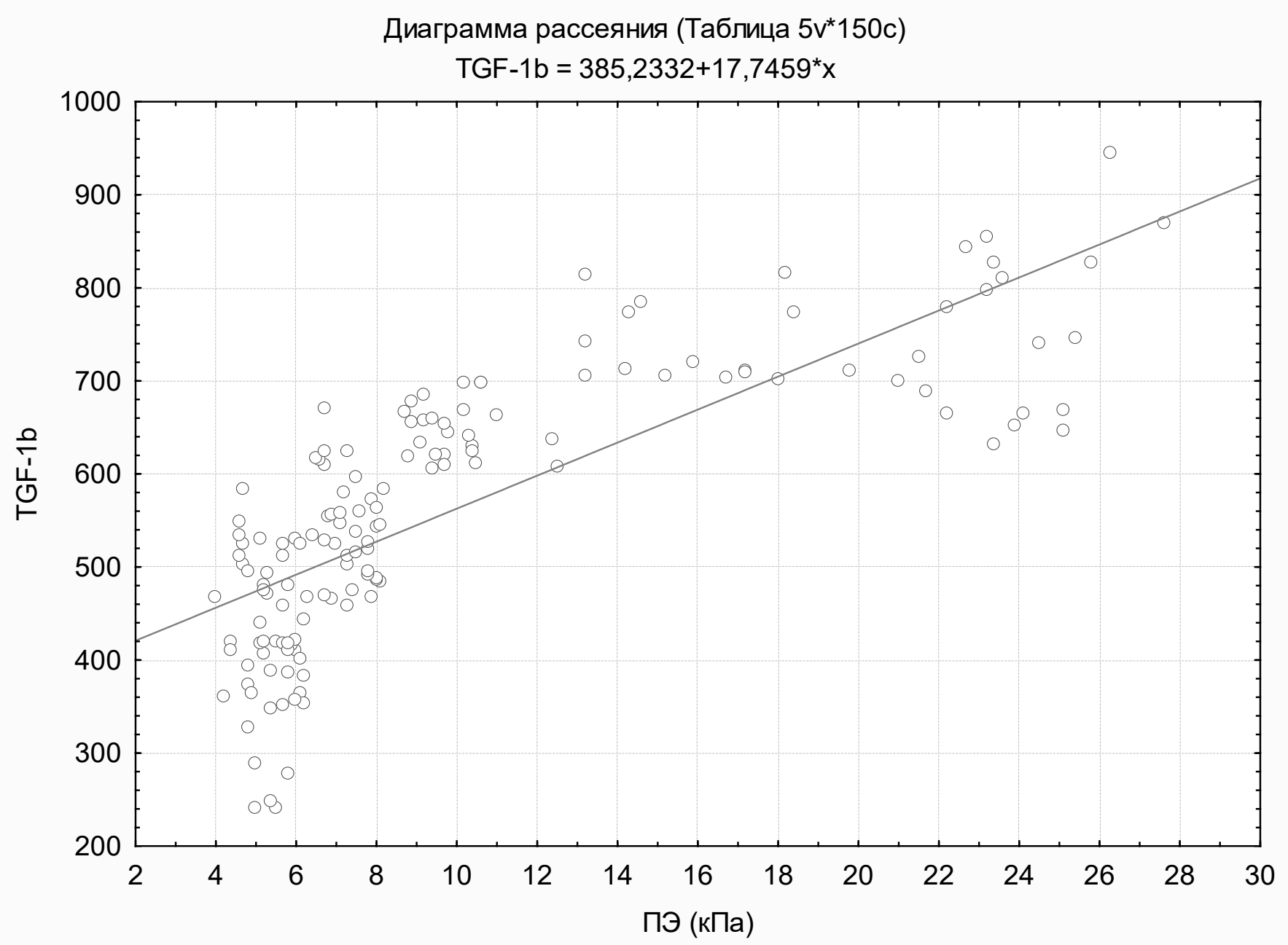

Рис. 5. Корреляционная связь между содержанием TGF- $\beta 1$ и стадией фиброза у больных XГ С.

дия фиброза печени по данным фиброэластометрии повышалась.

При сопоставлении уровня цитокинов и стадий фиброза печени, по данным фиброэластометрии, у больных ХГ С установлена статистически значимая связь $(p<0,01)$ между содержанием TGF- $\beta 1$ и ТИМП-1 в сыворотке крови, с одной стороны, и индексом фиброза, с другой ( $r=0,78$ и $r=0,71)$.

Выявлено, что у больных ХГ С с стадией 0 фиброза печени, по данным фиброэластометрии, и стадией 0-1 уровень TGF- $\beta 1$ был значимо $(p<0,01)$ снижен по отношению с соответствующим показателем у пациентов с стадиями 2, 3 и 4 (471,4 491,$4 ; 641,8 \pm 29,9 ; 721,4 \pm 55,8$ и 753,8 $\pm 89,8$ пг/мл, соответственно) (рис. 5).

Аналогичные результаты были получены по содержанию ТИМП-1 в сыворотке крови у исследованных больных в зависимости от стадии фиброза печени по данным фиброэластометрии. При этом наблюдалось, что по мере нарастания стадии фиброза содержание ТИМП-1 также повышалось. Так, у больных ХГ С со стадией фиброза 3-4 уровень ТИМП-1 был значимо $(p<0,05)$ выше по сравнению с таковым у пациентов с фиброзом 0-I и II стадии $(915,5 \pm 131,6 ; 985,4 \pm 182,3$ и 673,6 $\pm 105,6 ; 822,1 \pm 177,7$ и нг/ мл, соответственно) (рис. 6).

Сравнительная характеристика сывороточных показателей цитокинов в зависимости от стадии фиброза печени по данным фиброэластометрии показана в таблице 4.

Таким образом, у исследованных больных ХГ С уровни TGF- $\beta 1$ и ТИМП-1 положительно коррелируют со стадией фиброза по данным фиброэластометрии [1,2].

Характеристика прогностической ценности сывороточных показателей цитокинов в зависимости от стадии фиброза печени по данным фиброэластометрии представлена в таблице 6. 
Таблица 4. Содержание цитокинов в сыворотке крови у больных ХГ С в зависимости от стадии фиброза по данным фиброэластометрии $(\mathrm{M} \pm \mathrm{SD})$

\begin{tabular}{|l|l|l|}
\hline Больные ХГ C & TGF- $\beta 1$, пгІмл. & ТИМП-1, нгІмл. \\
\hline стадия F0-F1 & $471,4 \pm 91,4$ & $673,6 \pm 105,6$ \\
\hline стадия F2 & $641,8 \pm 29,9$ & $822,1 \pm 177,7$ \\
\hline стадия F3 & $721,4 \pm 55,8$ & $915,5 \pm 131,6$ \\
\hline стадия F4 & $753,8 \pm 89,8$ & $985,4 \pm 182,3$ \\
\hline Контроль, n=35 & $257,3 \pm 58,9$ & $458,6 \pm 76,3$ \\
\hline & $p 1-2<0,05$ & $p 1-2<0,05$ \\
& $p 1-3<0,05$ & $p 1-3<0,01$ \\
& $p 1-4<0,01$ & p1-4<0,01 \\
& $p 2-3<0,05$ & $p 2-3<0,05$ \\
& $p 2-4<0,05$ & $p 2-4<0,01$ \\
& $p 3-4<0,05$ & $p 3-4<0,05$ \\
& $p 1-5<0,05$ & $p 1-5<0,05$ \\
& $p 2-5<0,01$ & $p 2-5<0,01$ \\
& $p 3-5<0,01$ & $p 3-5<0,01$ \\
& $p 4-5<0,01$ & $p 4-5<0,01$ \\
\hline
\end{tabular}

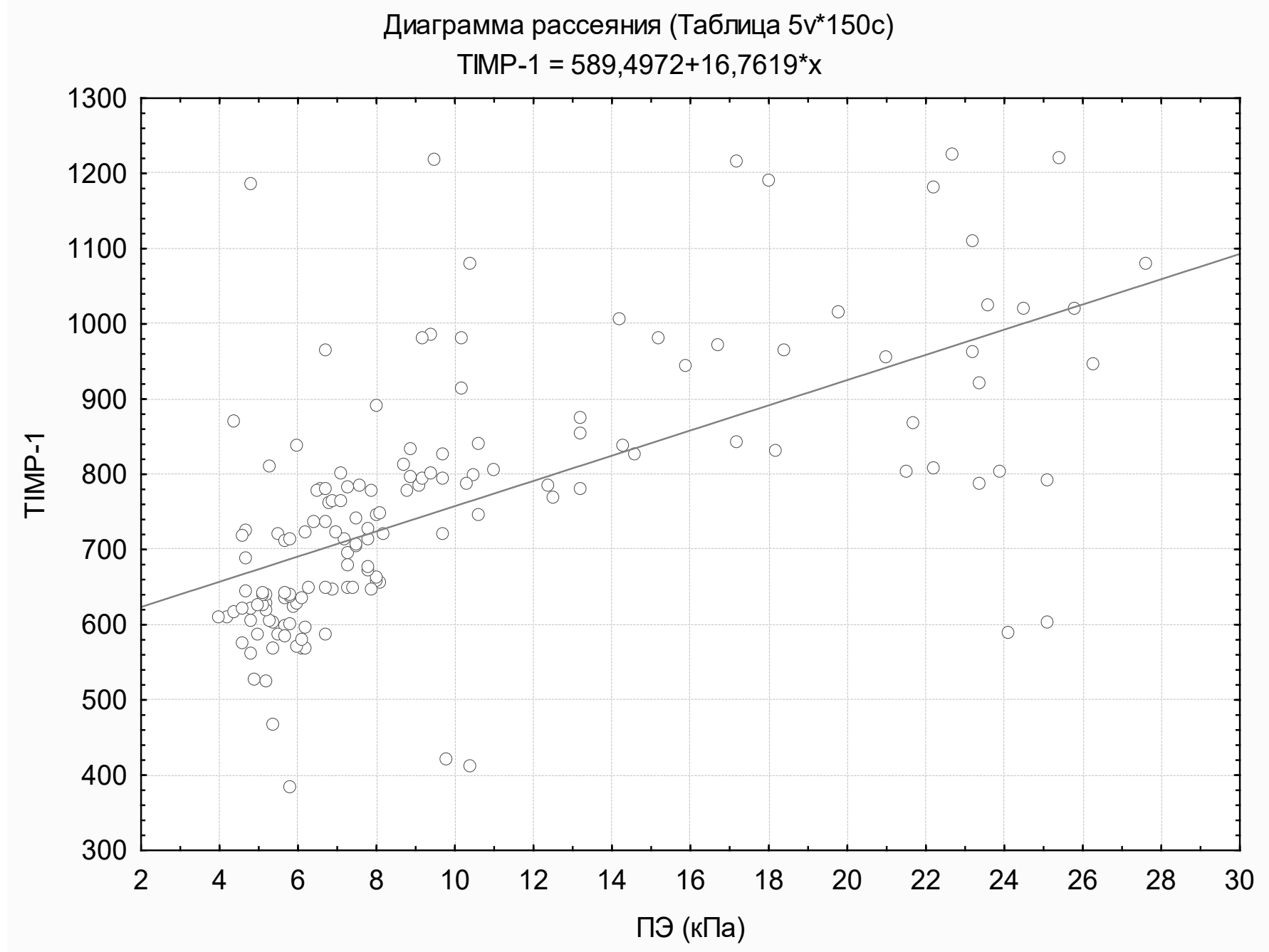

Рис. 6. Корреляционная связь показателя ТИМП-1 и стадии фиброза у больных ХГ С. 


\section{ЛИТЕРАТУРА}

1. Blomhoff R., Berg T., Norum K. R. Transfer of retinol from paren chymal to stellate cells in liver is mediated by retinol-binding protein // Proc. Natl. Acad. Sci. USA. 1998. V. 85. P. 3455-3458.

2. Bataller R., Brenner D. A. Liver fibrosis // J. Clin. Invest. 2005. V. 115. P. 209-218.

3. Павлов Ч. С., Золоторевский В. Б., Ивашкин В. Т. и др. Динамика показателей воспаления и фиброза печени у больных хроническим вирусным гепатитом С (ХВГ-С) на фоне комбинированной терапии (интерфероном-а + рибавирином) // Российский журнал гастроэнтерологии, гепатологии и колопроктологии. 2006. T. XVI, № 1. С. 45.— (Материалы XI Российской конференции «Гепатология сегодня»).

4. Шапиро И. Я., Сек Ок Сун, Кноринг Б. Е. Особенности иммунного ответа и цитокиновый статус при различных вариантах течения цирроза печени // Мединская иммунология. 2002. Т. 4, № 4-5. С. 545-552.

5. Ярилин, А. А. Система цитокинов и принципы ее функционирования в норме и при патологии // Иммунология. 1997. № 5. С. 7-13.

(с) Мусхаджиев Алимхан Абухаджиевич ( muskhadzhiyev76@list.ru ).

Журнал «Современная наука: актуальные проблемы теории и практики»

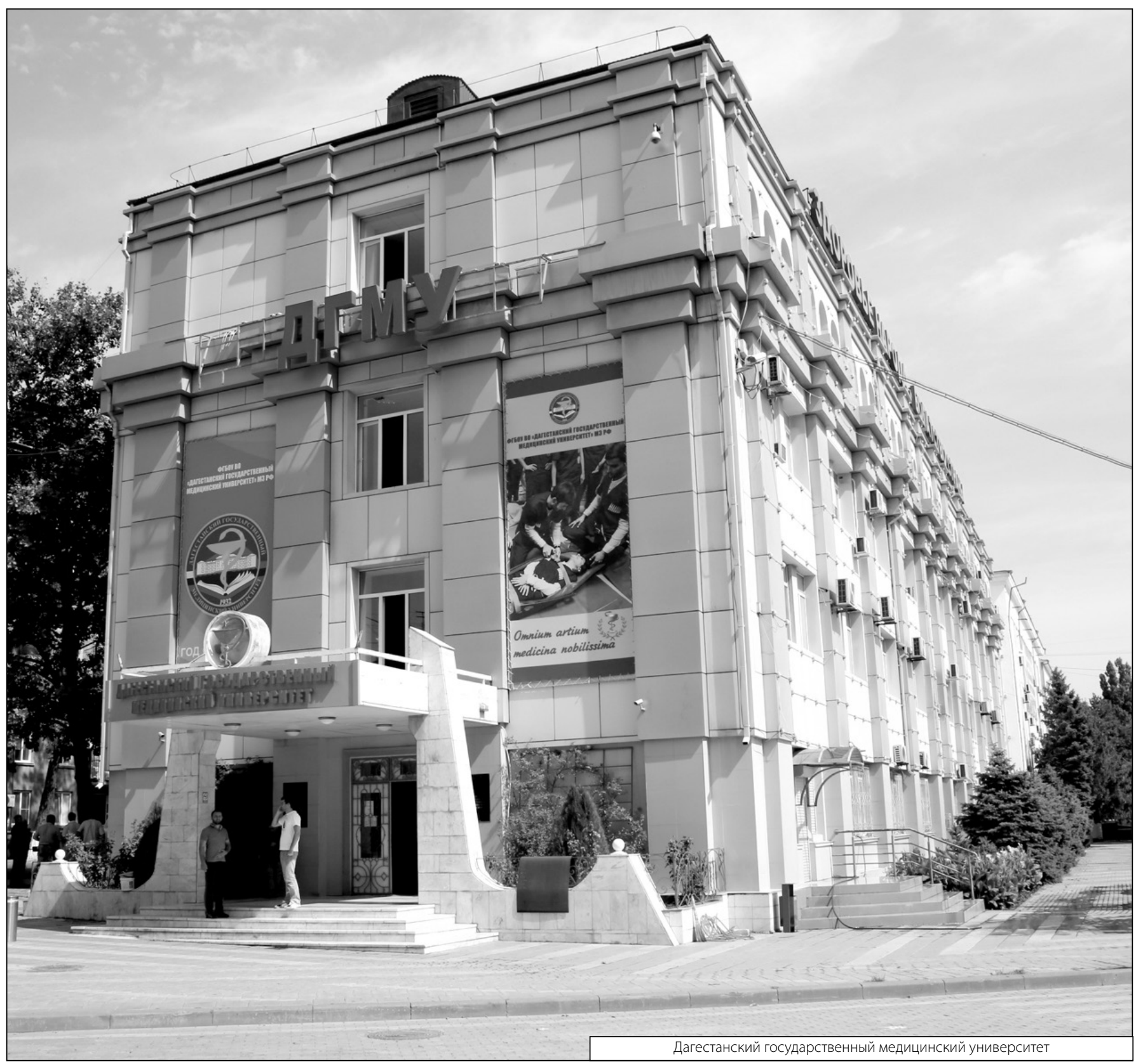

